Sharif University of Technology
Scientia Iranica
SCIENTIA
I RAN I C A
http://scientiairanica.sharif.edu

\title{
Collapse of reticulated domes: A case study of Talakan oil tank
}

\author{
A. Heidari*, H. Karimi, and I. Mahmoudzadeh Kani \\ School of Civil Engineering, Faculty of Engineering, Tehran University, Enghelab Ave., Tehran, Iran. \\ Received 28 June 2016; received in revised form 25 September 2018; accepted 21 January 2019
}

\section{KEYWORDS \\ Bifurcation point; Secondary path; Reticulated dome; Unstable buckling; Eccentric load.}

\begin{abstract}
In this paper, the instability of single-layer reticulated domes is discussed. This purpose is elaborated by a case study of Talakan oil tank dome, which is analyzed in this work with research package. This paper provides technical information on the design, fabrication, and collapse of Talakan dome. The secondary paths, especially in unstable buckling, can play an important role in the loss of stability and lead to structural failure. The authors show that the stiffness of the dome is not adequate for preventing buckling under the prescribed snow loads. It is also shown that the capacity of the dome to resist eccentric snow load is about half of its capacity to resist symmetric snow loads. Although six combinations of load and support fixity are included in design assumptions, considerable attention has been placed on the bifurcation behavior in Talakan dome. The stiffness of aluminum sheets of the roof cover has not been taken into account in the stability analysis.
\end{abstract}

(C) 2020 Sharif University of Technology. All rights reserved.

\section{Introduction}

Domes are characterized by many advantages from both structural and architectural points of view [1-3], and these advantages were comprehensively analyzed by Makowski [4]. Research on these structures has been quite hot in recent years [5]. Although linear static analysis shows domes' functionality in classical buildings, it is important that the nonlinearity, which contains both material and geometry [6], be considered in a full analysis $[7,8]$. The behavior of single-layer structures is highly nonlinear and is affected by diverse factors [1] such as mesh density, joint rigidity [9], the geometrical shape of domes, non-uniform loads,

\footnotetext{
*. Corresponding author. Tel.: +1514962 2600 E-mail addresses: heidari.alireza@ut.ac.ir (A. Heidari); hossein.karimi@ut.ac.ir (H. Karimi); imkani@ut.ac.ir (I. Mahmoudzadeh Kani)
}

doi: $10.24200 /$ sci. 2019.21239 support conditions, rigidities of the connection between members [10], slenderness ratio of members, halfsubtended angle for members, initial imperfection, etc. [11]. Furthermore, it is required to check for any traces of instability through nonlinear analyses [12-14]. Instability is one reason for the collapse of single-layer lattice domes, a comprehensive review of which was carried out by Dulácska and Kollár [15].

As mentioned earlier, non-uniform load, about which Kato and coworkers [11] are pioneers, is one of the collapsing reasons. Additionally, load collapse due to non-uniformity is affected by buckling, whether locally in elements or globally in the whole structure. Accordingly, buckling is one of the most important parameters in the structural design of single-layer reticulated domes $[2,16]$ because these domes are very sensitive to buckling and start to lose their load-bearing capacities after buckling [11].

Knowledge about stability behavior is one of the requirements for the investigation of nonlinear response of structures. In such an analysis, limit points and 
bifurcation points are very important and must be found by a standard procedure. For a bifurcation point, this means that all the branches emerging from the bifurcation point are of interest in the analysis [17]. The main difficulty in analyzing the stability behavior of a structure follows from the fact that the examined system of equations is singular at a limit point or a bifurcation point [18-20]. At a critical point, the structure may jump to an inverted equilibrium shape and load capacity reduces notably [21,22].

Buckling behavior can be interpreted as instability which is induced by a singular tangent-stiffness matrix [23,24]. This matrix is not constant throughout the deformation history of the structure. This is due to the effect of the material and geometric nonlinearities [14]. By considering the tangent-stiffness matrix and bifurcation path, the nonlinear analysis of the present structure, Talakan oil tank dome, is carried out by the technique provided by the authors in their previous work [14]. In this technique, a method for reliable detection and accurate computation of singular points on the load path is presented and applied to a space structure subjected to symmetric and asymmetric snow loads. In recent years, finite element method has been quite popular $[3,25,26]$. In the present work, the method is implemented in a materially and geometrically combined, nonlinear finite element analysis computer program based on an incremental/iterative Newton-Raphson solution procedure. it is necessary to mention that the effect of velocity [27] in loading is not assessed in this study.

Following brief explanations about bifurcation path, the construction of Talakan oil tank dome in Russia will be discussed. There are two reservoirs with $50000 \mathrm{~m}^{3}$ capacities individually for covering a circular area with aluminum sheets for oil tanks in Russia. The aluminum geodesic dome is a selfsupporting cover and is used usually in refineries and tank farms, where storage products and structural tank components are protected from atmospheric and environmental influences, while, at the same time, hazardous vapor emissions are minimized and water from entering the storage tanks is prevented. Each dome in Talakan is located on 78 supports. Nonetheless, they were damaged due to some design problems. The purpose of this article is to find the cause of destruction in Talakan oil domes. Figures 1 and 2 show a preview of Talakan oil domes. It is notable to mention that the present study is focused on a circular dome, but can be extended to other shapes such as cylindrical [28].

The most important issues concerning these structures are "geometry", "loading", and "connection and support". They are usually symmetric in geometry and structures with symmetry have played an important role not only in decades but also in centuries [23]. Another important factor in the geometry of domes

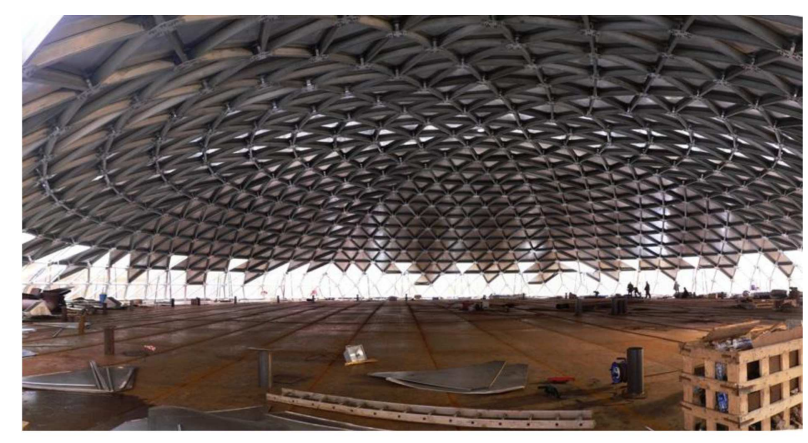

Figure 1. Installation of Talakan oil tank dome.

is the ratio of span to height [29]. Three factors are involved in the collapse of Talakan oil tank domes in parameters. These include geometric imperfections, secondary path in nonlinear unstable bucking, and connections.

\section{Construction}

The aluminum dome is a fully triangulated structure designed as a self-supporting dome roof whereby only its outer edge is connected to the tank shell around the outer rim. The domes are fabricated from highstrength aluminum alloys that resist corrosion as well as chemical, ultraviolet, and ozone degradation. Aluminum domes are generally constructed according to API 650 appendix G [30], i.e., the standard setting details of aluminum domes on storage tanks.

Reticulated domes such as Talakan, made of aluminum alloy, are often used for covering oil tanks. Typical domes in Talakan are characterized by the spherical surface with a diameter on the support from 30 to $60 \mathrm{~m}$ and the crest rising from 6 to $11 \mathrm{~m}$.

The structure used for covering the oil tank, which is discussed in this paper, is a single-layer reticulated dome, made of straight I-section elements with the material of aluminum alloy. The roof of the domes is made of aluminum sheeting fixed to the I-section element, and the supports of the domes are at the nodes of the lowest ring.

The stability of the dome being designed for dead, snow, and wind loads is of paramount importance for the ultimate load-bearing capacity of the structure. It is also necessary to calculate the effects of temperature changes and relative temperature at which the dome is built. The stability of the dome can be affected by the following design parameters:

- The radius of the spherical surface;

- The form of the dome meshes cells;

- The shape and area of the member cross-section;

- Design and construction of the connections at the nodes of the dome;

- Construction and condition of the supports. 


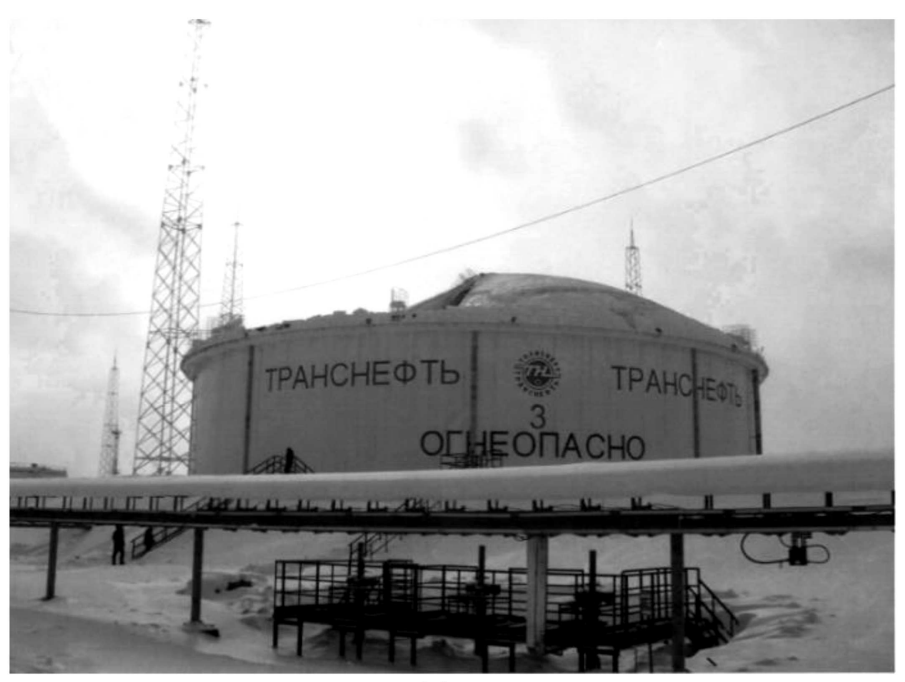

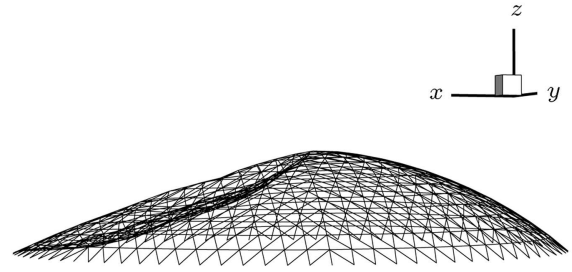

(b)

Figure 2. Collapsed dome: (a) Real photo and (b) simulated structure.

\section{Geometry}

The middle surface of the dome is a cap forming part of a sphere. The primary dimensions of the cap are as follows:

- Radius of the sphere $48.600 \mathrm{~m}$;

- Radius at the supports $30.000 \mathrm{~m}$;

- Height of the cap $\quad 10.364 \mathrm{~m}$.

The cap is subdivided into 14 rings that subtend equal angles at the midpoint of the sphere. The area of the dome is subdivided, as shown in Figure 3. The plan consists of six congruent sectors. Figure 4 shows the elevation in the direction of axis $y$.

All members are made of aluminum with modulus of elasticity of $7 \times 10^{7} \mathrm{kN} / \mathrm{m}^{2}$. The members on the outer perimeter are square boxes sized $200 \times 200 \mathrm{~mm}$ with a wall thickness rate of $12 \mathrm{~mm}$. The area of their

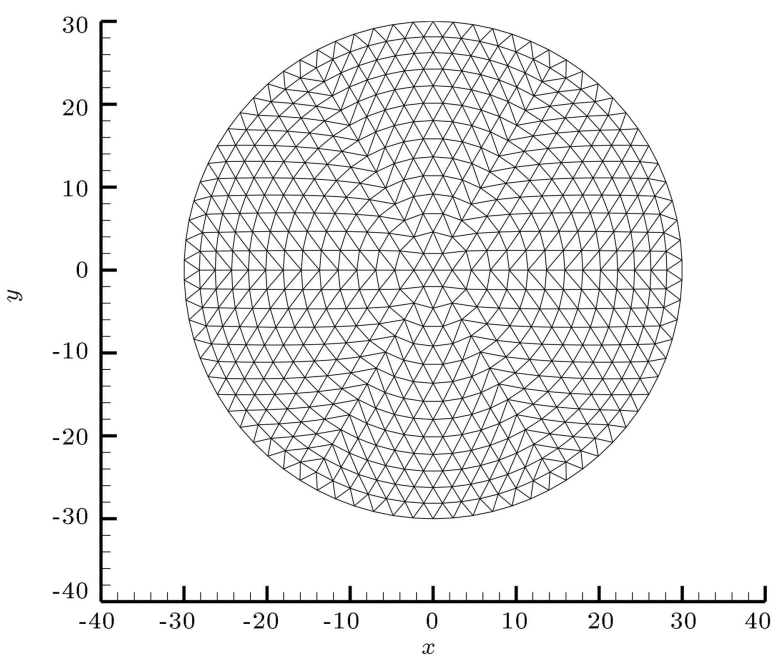

Figure 3. Planning the dome in the in-house Space-Frame software (all dimensions in $\mathrm{m}$ ).

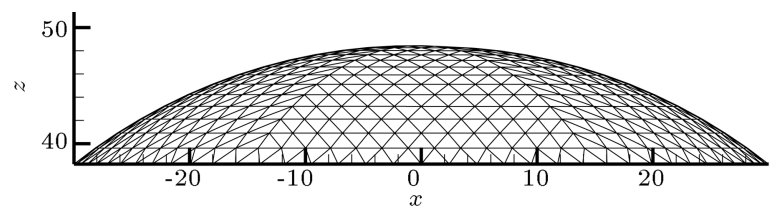

Figure 4. Elevation of the dome from in-house Space-Frame software (all dimensions in $\mathrm{m}$ ).

cross-section is $9024 \mathrm{~mm}^{2}$. All other members in the dome are I-sections with depth $200 \mathrm{~mm}$, flange width $100 \mathrm{~mm}$, web thickness $4.5 \mathrm{~mm}$, and flange thickness $6.0 \mathrm{~mm}$. The area of their cross-section is $2046 \mathrm{~mm}^{2}$. The dome is covered with $1.2 \mathrm{~mm}$ thick aluminum sheets. Figure 5 shows the cross-section of members.

\section{Loads}

The self-weight of the members is concentrated in the corresponding nodes. Their unit weight is taken as $27.1 \mathrm{kN} / \mathrm{m}^{2}$. The aluminum sheets covering the dome weigh $0.0342 \mathrm{kN} / \mathrm{m}^{2}$. The design value of the snow load is determined by the following formula [31]:

$$
S=S_{g} C_{e} C_{t} \mu
$$

where:

$S \quad$ Design snow load $\left(\mathrm{kN} / \mathrm{m}^{2}\right.$ of horizontal area)

$S_{g} \quad$ Design weight of snow $\left(2.4 \mathrm{kN} / \mathrm{m}^{2}\right.$ of horizontal area for Talakan)

$C_{e} \quad$ Pressure coefficient (1.0 for full enclosure)

$C_{t} \quad$ Temperature coefficient (1.0 for unheated roof)

$\mu \quad$ Pressure distribution factor. 


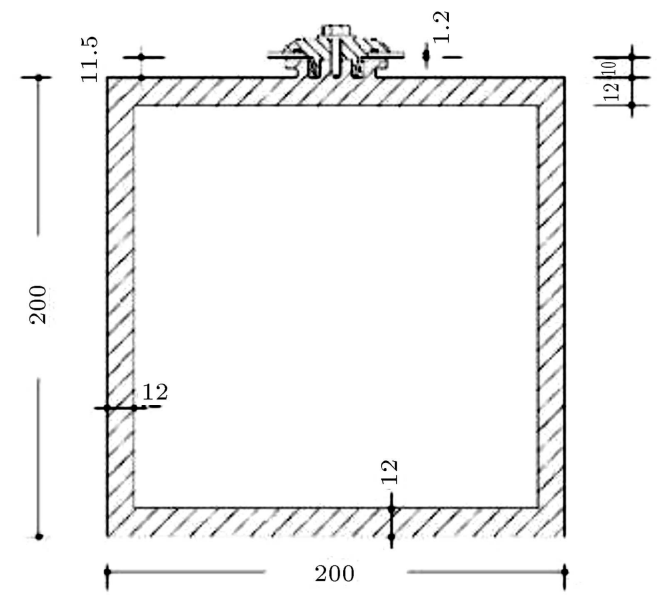

(a)

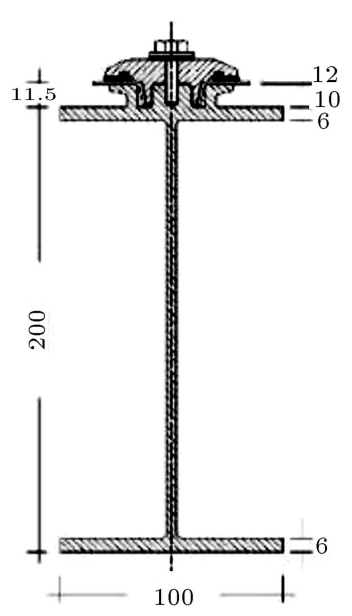

(b)

Figure 5. (a) Ring members connected to vertical supports and (b) typical dome members (all dimensions in mm).

Let the radius at which the tangent to the crosssection of the dome makes an angle of 30 degrees with the horizontal be denoted by $r_{30}$. Three cases are considered for the pressure distribution factor:

Case 1: Symmetric snow load.

$r \leq r_{30}: \quad \mu=1.0$

$r>r_{30}:$ Linear variation from $\mu=1.0$ at

$$
r=r_{30} \text { to } \mu=0.74 \text { at } r=r_{\text {support }}
$$

Case 2: Eccentric snow load. The snow load is assumed to be eccentric in the direction of the positive $x$ axis. The second and third quadrants of the plan of the dome are unloaded. The pressure distribution factor in the first and fourth quadrants depends on the angle $\beta$ and the distance $z$ from the axis of the dome, as defined in Figure 6:

$$
\begin{aligned}
& r \leq r_{30}: \quad \mu=2.36\left(\frac{z}{r_{30}}\right)^{2} \sin \beta, \\
& r>r_{30}: \quad \text { linear variation from } \mu=2.36 \\
& \text { at } r=r_{30} \text { to } \mu=1.87 \text { at } r=r_{\text {support }}
\end{aligned}
$$

Case 3: Eccentric snow load. The snow load is assumed to be eccentric in the direction of the positive $x$ axis. The second and third quadrants of the plan of the dome are unloaded. The pressure distribution factor in the first and fourth quadrants depends on the angle $\beta$ and the distance $z$ from the axis of the dome, as defined in Figure 6.

$$
\mu=3 \sin \beta \sqrt{\frac{2 f}{d} \sin 3 \alpha},
$$

where:

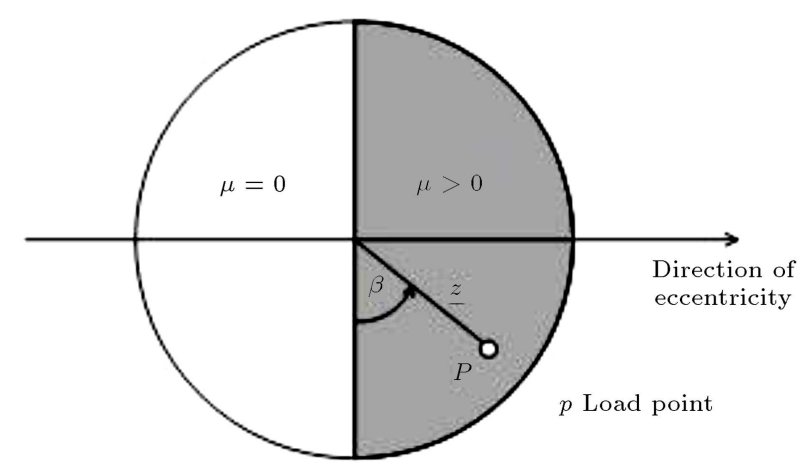

Figure 6. Variable definition for eccentric load.

$\alpha \quad$ is $\arcsin \frac{z}{R}$;

$f \quad$ Height of the dome;

$d \quad$ Diameter of the dome on the support;

$R \quad$ Radius of the sphere.

These three cases are shown schematically in Figure 7 .

\section{Supports}

The dome is supported at every node on its outer perimeter. Two support cases are considered as follows:

Fixed Each node on the perimeter is fixed against translation in the direction of each of the three coordinate axes

Free $\quad$ Each node is fixed against translation in the vertical direction

The perimeter node on the positive $x$ axis is fixed against translation in both horizontal directions. The perimeter node on the negative $y$ axis is fixed against translation in the direction of axis $x$.

The fixed supports model a situation where thering members, the wall of the tank, and the studs are 


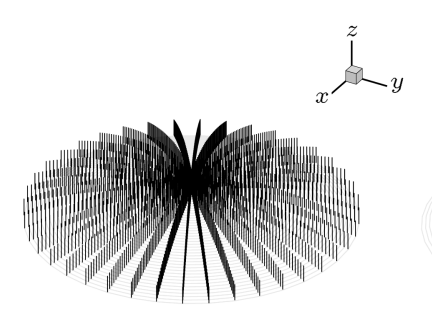

(a)

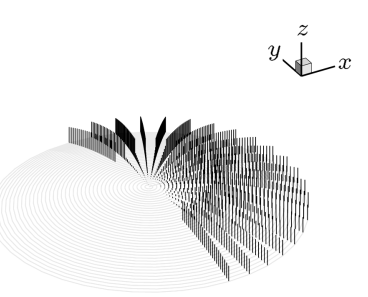

(b)

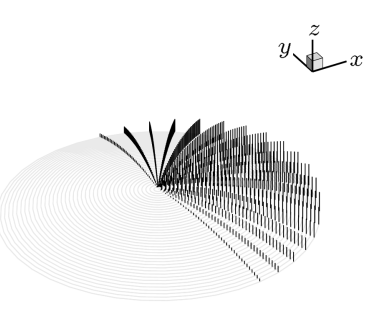

(c)

Figure 7. Schematic figures of snow load cases: (a) Load Case 1, (b) Load Case 2, and (c) Load Case 3.
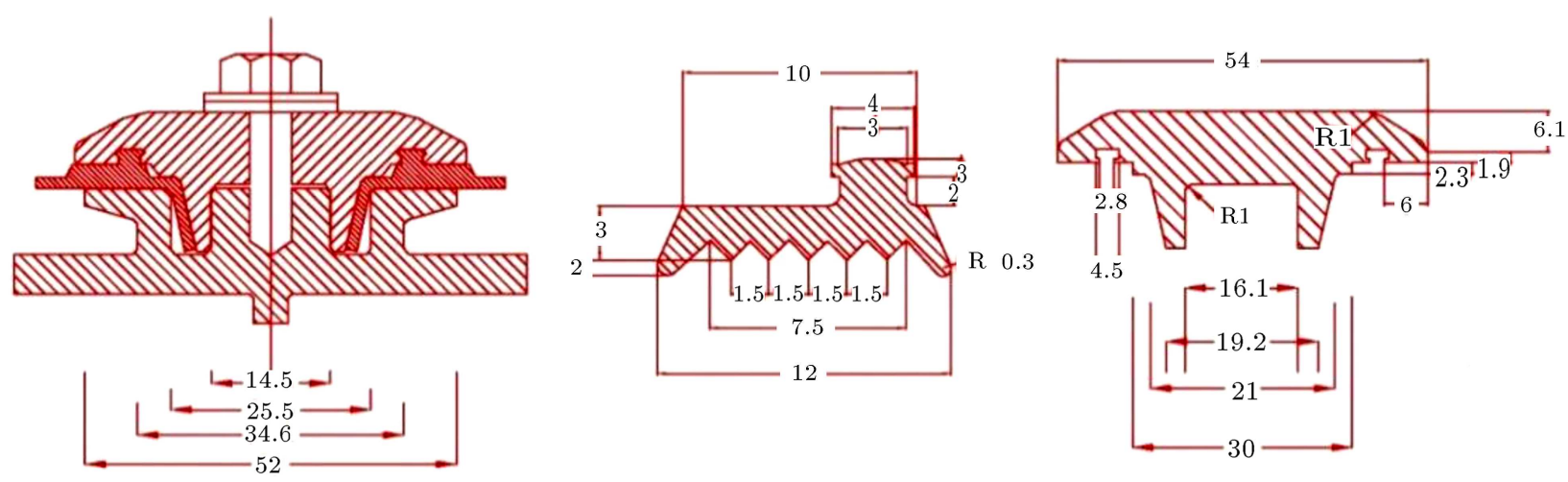

Figure 8. Bolted connections of aluminum sheets to members (all dimensions in mm).

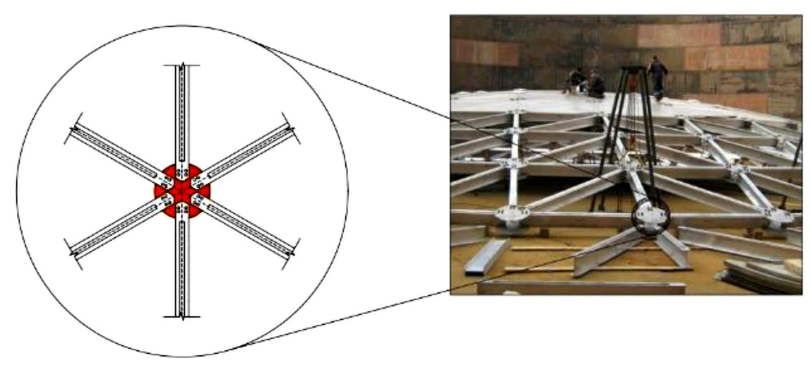

Figure 9. Member connections in Talakan domes.

so rigid that they prevent horizontal motion at the perimeter of the cap.

The free supports prevent the translation of the dome as a rigid body on the horizontal plane, but allow the outer perimeter to change its shape (extension of the members in the outer ring).

The real support of the dome in the structure is intermediate between the two cases that are analyzed here. Well-designed joints are essential for the satisfactory performance of a structure. In aluminum frameworks with riveted or bolted gusset plates, it has been estimated that the weight of the joints is about $20-30 \%$ of the weight of the structure; in cost terms, the ratio is much larger [32]. In Talakan, dome connections are made by bolting. Figures 8 and 9 show the connections used in Talakan.

\section{Generator}

The nodes, members, supports, loads, and load combi- nations of the dome are generated for the analysis by the software. The topology of the nodes and members is described with the ring and line numbers defined in Figure 10. The rings are numbered consecutively from 0 at the apex to 14 at the perimeter.

The number of nodes for rings 1 to 13 is 6 times the ring index. Ring 0 has 1 node (the apex), and ring 14 has the same number of nodes as ring 13 . The node on the $x$-axis of a specific ring has line number 0 . The nodes are shifted by half an interval in the anticlockwise direction only in ring 14 . The line numbers of the other nodes on the same ring are consecutive in the counter-clockwise direction.

The location of a node is denoted by the ordered pair (ring, line). The initial numbering of the nodes starts with 0 at the apex, followed by the nodes in ring 1 in the order of their line numbers. The numbering continues with rings 2 to 14 . The node with number $\mathrm{k}$ is denoted by "nk" so that node 47 is named "n 47 ". The ordering of the nodes in the system equations differs from the numbering introduced here, which will be discussed later in this paper.

A member is identified based on the number of its start and end nodes. If a node number has less than 3 digits, it expands with leading digits 0 . The member from node $\mathrm{k}$ to node $\mathrm{m}$ is denoted by "bkm" so that the member from node 24 to node 7 is denoted by "b024007".

The supports at a node whose number has the digits xyz are named "sxyzX1", "sxyzX2", and "sxyzX3". The vertical load at node xyz is called "Lxyz". 

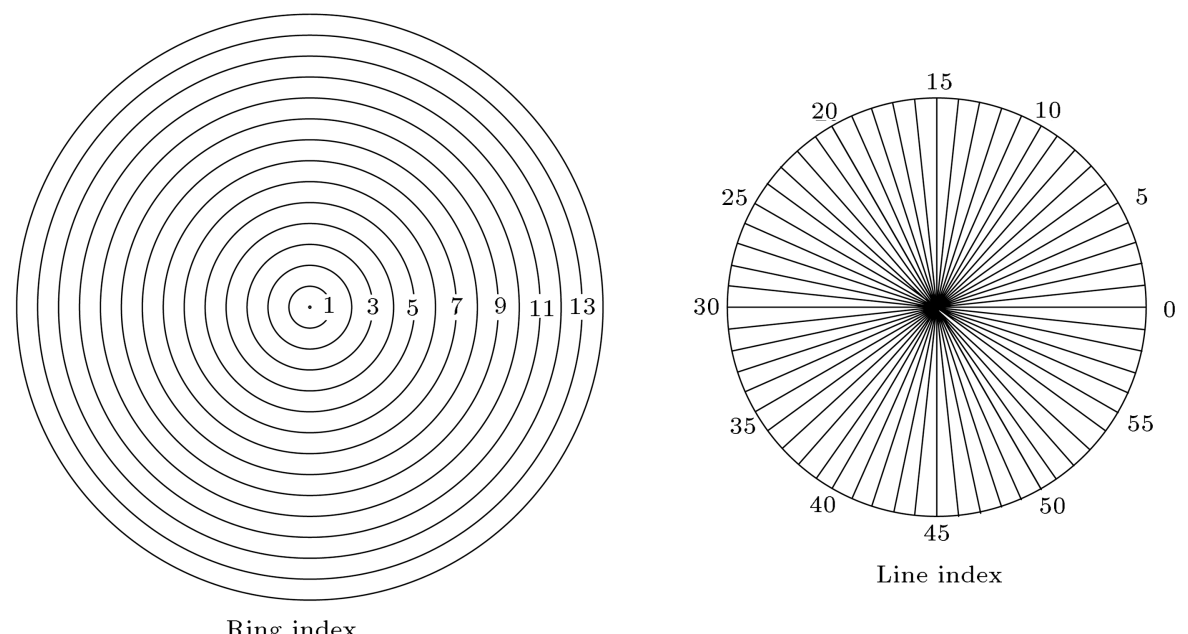

Figure 10. Ring and line indices for the plan of the dome.

The nodes are generated in the sequence of their numbers. The members and the tri-angular facets of the roof cover are generated per sector in a ring. The sectors are numbered consecutively from 0 to 5 in the counter-clockwise direction, starting with 0 on the $x$ axis. For rings 1 to 13 , the members and facets in the sector $\mathrm{s}$ are generated according to the rules in Figure 11.

The members and facets in the outer ring 14 are generated independently of the segments. The indices for a typical interval are shown in Figure 12.

The self-weight of the members is computed in a cycle over all members and added per node. The weight of the roof cover is computed in a cycle over all
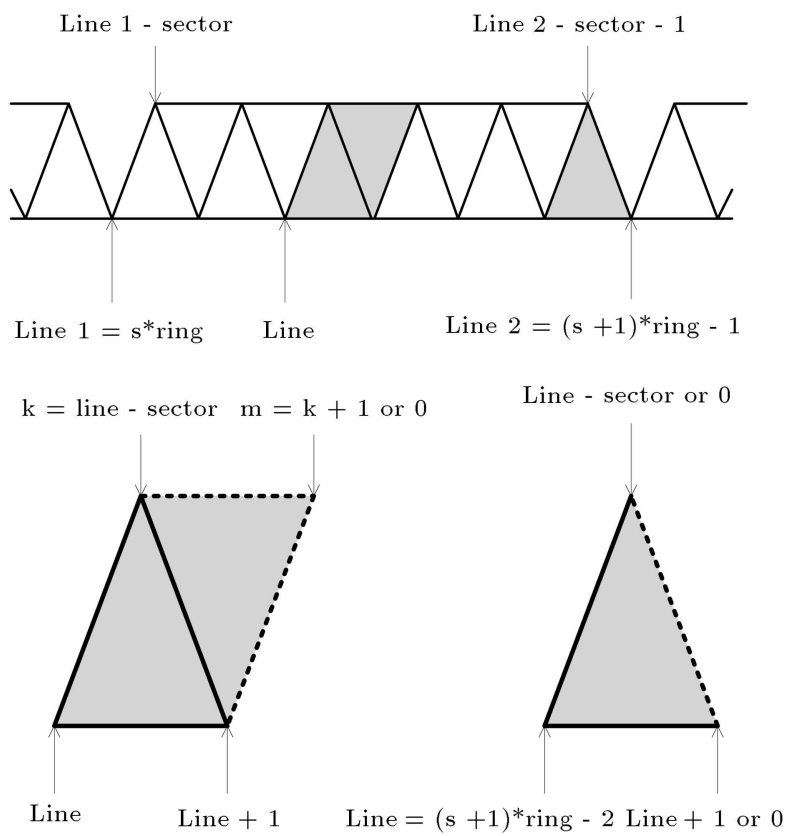

Figure 11. Members and facets in a sector of a ring in the range of $1 \leq \operatorname{ring} \leq 13$.

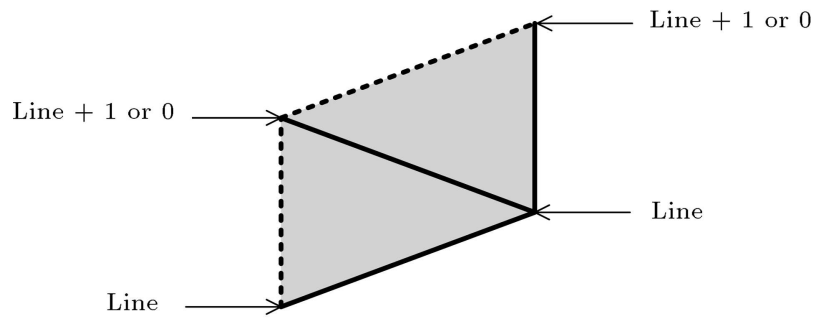

Figure 12. Members and facets in ring 14.

triangular facets. One third of the weight of a facet is attributed to each of its nodes. The snow load is also computed in a cycle over the facets. The snow load intensity is computed at the midpoint of the facet. One third of the load on the facet is attributed to each node.

\section{Population of the system equations}

The numbering of the nodes in the generator leads to a system stiffness matrix with a nearly triangular band structure. The band is narrow at the apex displacements and wide at the support displacements. The number of multiplications required to decompose the matrix is given approximately by the following formula:

$$
N \cong \frac{1}{2} \sum_{i=1}^{n_{R}}\left(k_{i}+6\right)^{3}
$$

where:

$N \quad$ Number of multiplications for decomposition of the stiffness matrix

$k_{i} \quad$ Number of degrees of freedom in ring $i$

$n_{R} \quad$ Number of rings in the dome

The number of degrees of freedom in ring $i$ is a function of the ring index:

$$
k_{i}=i n_{S} n_{F},
$$


where:

i Ring index

$n_{S} \quad$ Number of sectors per ring 6

$n_{F} \quad$ Number of degrees of freedom per node 3

Substituting Eq. (2) into Eq. (1) yields the following:

$$
N \cong \frac{1}{2} 6^{3} \sum_{i=1}^{15}(3 i+1)^{3}=45.7 \times 10^{6} \text { operations. }
$$

Since the system matrix is decomposed at least twice per load step and 80 load steps (in order) for one analysis, the nodes are renumbered to reduce the solution effort. A wavefront algorithm is used for this purpose. The number of operations required for decomposition is given approximately as follows:

$$
N_{w} \cong \frac{1}{2} \sum_{w=1}^{n_{W}}\left(k_{w}+6\right)^{3}
$$

where:

$N_{w} \quad$ Number of multiplications for decomposition with wave front numbering

$k_{w} \quad$ Number of degrees of freedom in wave front $w$

$n_{w} \quad$ Number of wave fronts in Figure 7

The number of degrees of freedom in the wavefronts is:

$$
k_{w}=3 n_{N w}+6
$$

where $n_{N w}$ is the number of nodes in wave front $w$.

Substituting Eq. (5) into Eq. (4) yields the following:

$$
N_{W} \cong \frac{1}{2} 3^{3} \sum_{i=1}^{15}\left(n_{N w}+4\right)^{3}=7.17 \times 10^{6} \text { operations. }
$$

The number of multiplications for the decomposition of the stiffness matrix is reduced by a factor of 6.4 through the use of the wavefront renumbering algorithm. The time required for determining a complete load path up to the unstable state is approximately 8 seconds by a conventional laptop computer.

\section{Load combinations}

The self-weight of the dome including its sheeting is added to all load combinations with a factor of 1.10 . Each of the three snow load cases described in Section 2 is combined with each of the two support cases described in Section 3. Two models for space truss and space frame analysis of the dome were established. This leads to 12 load and model combinations, shown in Table 1. Of note, temperature loads are not considered in the analysis.

To analyze these combinations, in-house or research packages developed by the authors were used. In these packages, the first bifurcation point can be found in the unstable buckling mode with the use of frame elements with six degrees of freedom.

The physically nonlinear part is based on threedimensional von Mises based plasticity with return mapping to the yield surface. The geometrically nonlinear part is based on an updated Lagrangian large-deflection small-strain formulation [33]. In the package, space-truss bifurcation point can be found in the stable buckling mode through truss elements by three degrees of freedom. The final package also used is commercial software, ANSYS (registered by Mahabghods Company). Four analyses were carried

Table 1. Load and model combinations details.

\begin{tabular}{cccccccc}
\hline \multirow{2}{*}{$\begin{array}{c}\text { Load and model } \\
\text { combinations }\end{array}$} & $\begin{array}{c}\text { Self-weight } \\
\text { multiplier }\end{array}$ & Snow load & \multicolumn{2}{c}{ Supports } & \multicolumn{2}{c}{ Element } & In-house \\
\cline { 4 - 6 } case & Free & Fixed & Truss & Frame & package \\
\hline C1 & 1.1 & 1 & - & $*$ & $*$ & - & Space truss \\
C2 & 1.1 & 2 & - & $*$ & $*$ & - & Space truss \\
C3 & 1.1 & 3 & - & $*$ & $*$ & - & Space truss \\
C4 & 1.1 & 1 & $*$ & - & $*$ & - & Space truss \\
C5 & 1.1 & 2 & $*$ & - & $*$ & - & Space truss \\
C6 & 1.1 & 3 & $*$ & - & $*$ & - & Space truss \\
C7 & 1.1 & 1 & - & $*$ & - & $*$ & Space truss \\
C8 & 1.1 & 2 & - & $*$ & - & $*$ & Space truss \\
C9 & 1.1 & 3 & - & $*$ & - & $*$ & Space truss \\
C10 & 1.1 & 1 & $*$ & - & - & $*$ & Space truss \\
C11 & 1.1 & 2 & $*$ & - & - & $*$ & Space truss \\
C12 & 1.1 & 3 & $*$ & - & - & $*$ & Space truss \\
\hline
\end{tabular}


out with ANSYS. These analyses include (1) stable buckling mode with truss elements, (2) stable buckling mode with frame elements, (3) limit point mode with truss elements, and (4) limit point mode with frame elements. In the present work, the stable buckling mode with frame elements in ANSYS will be shown to compare how these commercial packages cannot detect the singular points on the load path of the dome.

\section{Summary of the results of the analysis for truss models}

The load that is generated for a load combination is regarded as a load pattern. The load pattern is multiplied by a load factor to yield the load that is acting on the dome. For each of the load combinations, the load factor that leads to instability has been determined. A maximum load factor of 1.0 implies that the dome buckles at the load of the load pattern.

The initial load factor increment per load step is 0.002 . The number of steps required to reach instability is determined by the solution algorithm. The maximum load factors $L F_{\max }$ for the load combinations are shown in the second column of Table 2. The maximum snow load intensity $q_{\max }$ corresponding to the maximum load factor is shown in column 3. It is computed as the product of the design weight of snow $S_{e}$ with the maximum value of the pressure distribution factor $\mu_{\max }$ and the maximum load factor $L F_{\max }$ for the load combination:

$$
q_{\max }=S_{e} \mu_{\max } L F_{\max } .
$$

Also shown are the displacement coordinates $u_{1}, u_{2}, u_{3}$ of the node "n469" (which lies on axis $x$ in ring 13) for the singular configuration of the dome. The buckling of the shell is initiated at this node in all six load combinations.

The very low load factors obtained demonstrate that the assumption of space truss behavior is not valid for this structure.

\section{Summary of the results of the analysis for frame models}

The maximum load factors $L F_{\max }$ for the next six com-

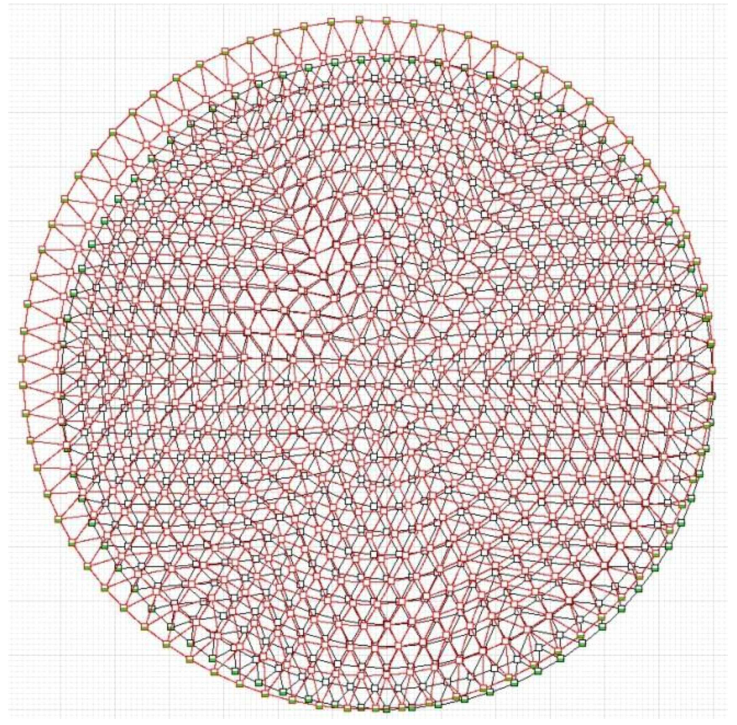

Figure 13. Singular configuration, C4.

Table 3. Summary of the stability analyses of the dome.

\begin{tabular}{cc}
\hline Combination & $\boldsymbol{L}_{\max }$ \\
\hline $\mathrm{C} 7$ & 2.182 \\
$\mathrm{C} 8$ & 1.234 \\
$\mathrm{C} 9$ & 1.402 \\
$\mathrm{C} 10$ & 1.492 \\
$\mathrm{C} 11$ & 0.852 \\
$\mathrm{C} 12$ & 1.000 \\
\hline
\end{tabular}

binations ( $\mathrm{C} 7$ to $\mathrm{C} 12)$ are shown in the second column of Table 3. This table shows the load factor whose dome reaches a singular configuration. Furthermore, to clarify how the commercial programs work in such structures, one model was established by ANSYS and the load factor was compared. The load factor found by ANSYS is $L F_{\max }=2.500$ in the combination $\mathrm{C} 7$.

Figures 13 and 14 show screenshots that illustrate the behavior of the dome.

\section{Conclusions}

The analysis clearly shows that the stiffness of the dome is not adequate to prevent buckling under the

Table 2. Summary of the stability analyses of the dome.

\begin{tabular}{cccccc}
\hline Combination & $\boldsymbol{L} \boldsymbol{F}_{\max }$ & $\boldsymbol{q}_{\max }\left(\mathbf{k N} / \mathbf{m}^{\mathbf{2}}\right)$ & $\boldsymbol{u}_{\boldsymbol{1}}(\mathbf{m m})$ & $\boldsymbol{u}_{\mathbf{2}}(\mathbf{m m})$ & $\boldsymbol{u}_{\mathbf{3}}(\mathbf{m m})$ \\
\hline C1 & 0.285 & 0.684 & -12.1 & 0 & -16.9 \\
C2 & 0.128 & 0.725 & -16.2 & 0 & -22.1 \\
C3 & 0.156 & 0.666 & -15.2 & 0 & -20.9 \\
C4 & 0.198 & 0.475 & -23.1 & 0 & -31.4 \\
C5 & 0.109 & 0.617 & -22.2 & 0.1 & -30.1 \\
C6 & 0.125 & 0.534 & -14.1 & 0.1 & -20.2 \\
\hline
\end{tabular}




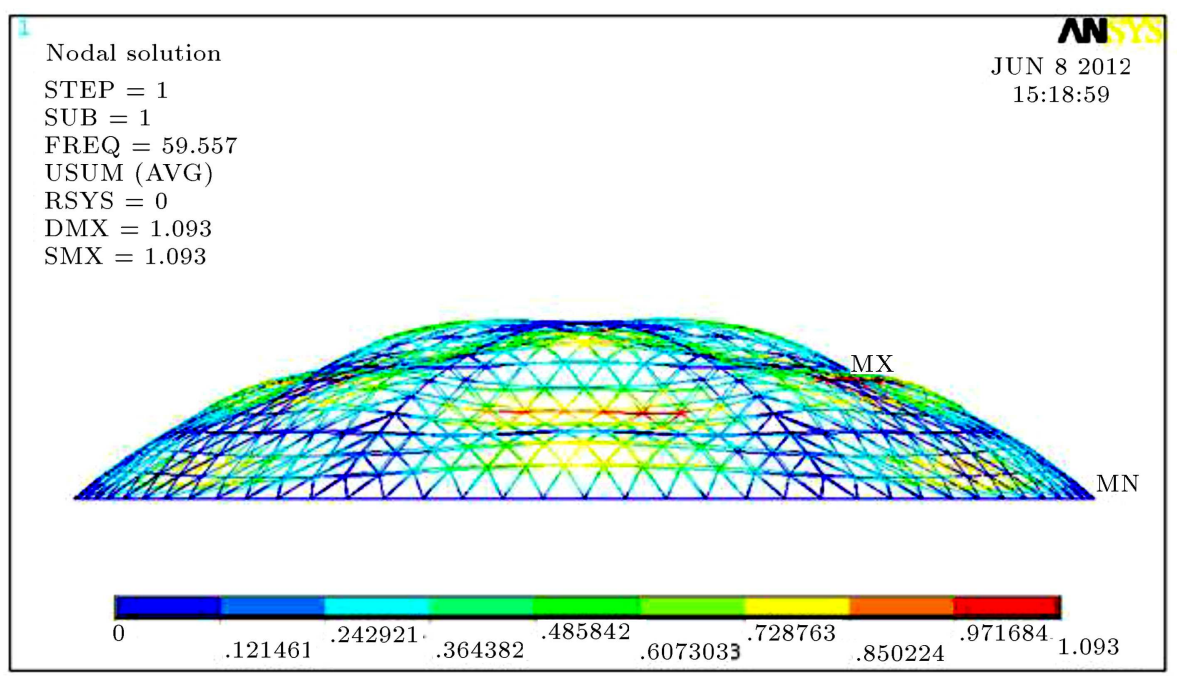

Figure 14. The first buckling mode shape in ANSYS for the frame element model, C7.

prescribed snow loads. The computed load factors shown in Table 2 vary from 0.109 for the combination $\mathrm{C} 5$ to 0.285 for the combination $\mathrm{C} 1$. The required value of the maximum load factor in each load combination shall be at least 1.0. This table also shows that the capacity of the dome to resist eccentric snow load is about half of its capacity to resist symmetric snow loads. The load-carrying capacity with fixed supports exceeds the capacity with free joints by $30 \%$ for symmetric snow load and by 15 to $20 \%$ for eccentric snow load. However, as mentioned earlier, the very low load factors obtained demonstrate that the assumption of space truss behavior is not really valid for this structure.

The case $\mathrm{C} 11$ in Table 3 , with $L F_{\max }=0.852$, constitutes the reason for collapse of the Talakan dome. This lead combination corresponds to the free system of support nodes aggravated by the heavily unsymmetrical snow loading pattern depicted by load Case 2 in Figure 7. A careful consideration of Table 3 shows that all the factors of safety are greater than 1 for load combinations $\mathrm{C} 7, \mathrm{C} 8$, and $\mathrm{C} 9$, where the support nodes are assumed to be fixed regarding all translational degrees of freedom. In load cases C10 to $\mathrm{C} 12$, only vertical restraint is assumed on the support nodes together with some extra global restraints to remove rigid body motions.

A substantial drop is observed in the factor of safety, even for load case C10 where symmetrical snow loading is applied to the structure, coming down from 2.182 to 1.492 . To ensure the proper and expected behavior of any shallow reticulated dome, the existence of an adequate horizontal restraint at the supports is a must. It appears that the axial stiffness of ring members depicted in Figure $5(\mathrm{a})$ could not perform this duty adequately for the huge Talakan dome. This deficiency together with the unsymmetrical snow load

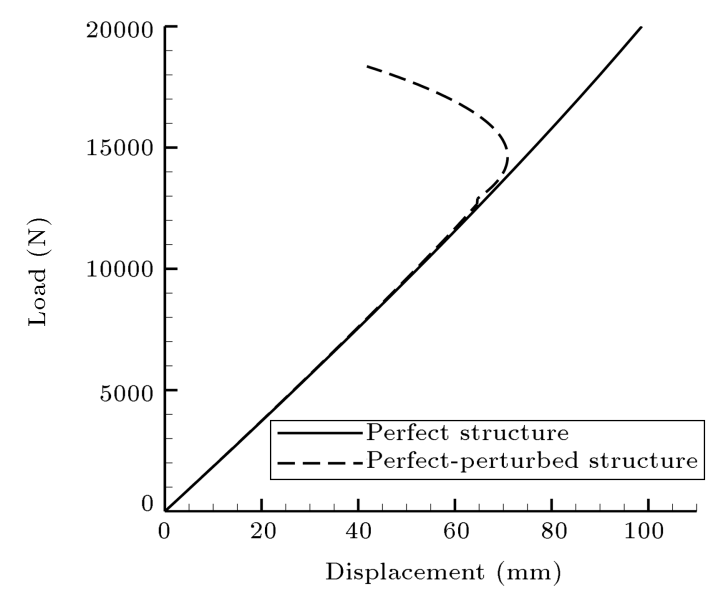

Figure 15. Load-displacement of the dome for the center node.

case of Figure 7(b) knocked down the safety factor to 0.852 of the case C11 in Table 3. Considering the selfweight multiplier of 1.1 in Table 1 , this undeniably low factor of safety could be reasonably increased to $0.852 \times 1.1=0.937$, a value not large enough to rescue the enormous Talakan oil tank of Figure 2 from inevitable collapse in the rather snowy weather of Siberia. The true limit load of an as-built dome, owing to the existence of initial imperfections in its construction, is always below the limit load of its primary equilibrium path. This knock-down effect may be quite substantial if there is a bifurcation point in the "perfect analysis" of the dome with the as-designed geometry and perfect connections. Analysis showed that although connections were assumed perfect, the stability of dome was not sufficient under the prescribed loads. Therefore, it was concluded that the main reason for the collapse of Talakan oil dome was the secondary path and low buckling load resistance in elements. In Figure 15, the load-displacement curve of center node 


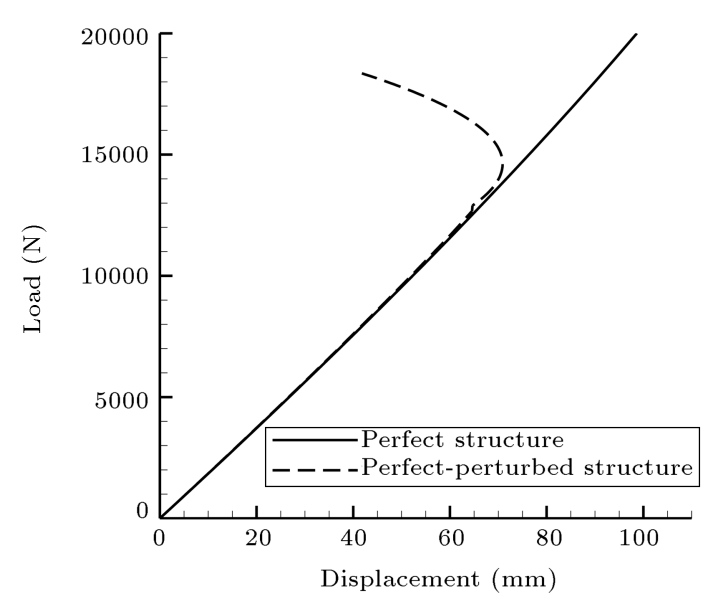

Figure 16. Angle change between adjacent members at the node $\mathrm{n} 469$.

for Talakan dome is shown. In this figure, the perfect and secondary paths are plotted.

The primary reason for the low buckling load is the little difference in the direction of the members that meet at a node such as "n469". The consequences of this geometric property are illustrated in Figure 16. For $R=48.6 \mathrm{~m}$ and $\Delta \theta=2.72$ degrees, the elevation of node "n469" above the secant between nodes "n397" and " $n 547$ " is given below:

$$
\begin{aligned}
h & =R(1.0-\cos \Delta \theta) \\
& =48.6(1.0-0.998873)=0.0547 \mathrm{~m} .
\end{aligned}
$$

The stability theory of a regular 2-member truss under vertical load shows that a vertical displacement of $42.3 \%$ of the height of the truss leads to snap-through behavior. A displacement of the order of magnitude $0.423^{*} 0.0547=0.0286 \mathrm{~m}$ of node " $\mathrm{n} 469$ " relative to the nodes "n397" and " 547 " in the direction to the midpoint of the sphere is thus sufficient to cause instability. The small-angle change $\Delta \theta$ is a consequence of the large radius of the sphere, given a member length of approximately $2.3 \mathrm{~m}$. The question arises whether a dome with this large radius should be conceived as a single-layer space truss.

The results of the analyses show that the displacements prior to buckling are small. They cannot serve as indicators of imminent instability. The displacements of the node "n469" tend to be significantly larger than the displacements of the neighboring nodes not only at instability but also at loads which are smaller than the buckling load. This may be attributed to the geometric pattern of the members in the vicinity of node " $n 469$ ".

Changes in the direction of the diagonal members in the $x$ axis lead to discontinuity in the stiffness of the shell along axis $x$. It is well known from shell theory in which discontinuities in stiffness lead to unfavorable bending moments. These moments cause transverse displacements, which increase the tendency of the shell to buckle locally.

As seen previously in this paper, the same truss is analyzed with a commercial software package. The nonlinear structural analysis algorithm of this package does not detect the singular points on the load path of the dome. It could be a notable challenge in designing such structures with a high ratio of snow load compared to their dead loads. General-purposenonlinear-computer programs that do not contain an option to obtain the lowest bifurcation path should be used with great caution by designers who are dealing with the analysis of shallow reticulated domes or other similar structures.

The snow load intensity under which the dome buckles in the field can exceed the computed snow loads due to secondary load-carrying mechanisms that are not included in the space truss analysis as presented in this report.

In these analyses there are two limitations that cause:

1. The joints of the structure may be able to transmit bending moments. This will increase the buckling load. The degree of improvement depends on the detailing of the joints;

2. The stiffness of the aluminum sheets of the roof cover has not been taken into account in the stability analysis. While the thin sheets cannot resist significant compressive stresses, they are capable of resisting tension fields.

This can lead to an increase in the buckling load. Additional insight into the stability behavior of the dome can be obtained by means of the interactive graphical user interface of the software, which allows the presentation of the behavior of all components of the dome at all points of the load path.

\section{References}

1. López, A., Puente, I., and Serna, M.A. "Direct evaluation of the buckling loads of semi-rigidly jointed single-layer latticed domes under symmetric loading", Engineering Structures, 29(1), pp. 101-109 (2007).

2. Guan, Y., Virgin, L.N., and Helm, D. "Structural behavior of shallow geodesic lattice domes", International Journal of Solids and Structures, 155, pp. 225239 (2018).

3. Kaveh, A. and Rezaei, M. "Topology and geometry optimization of single-layer domes utilizing $\mathrm{CBO}$ and ECBO", Scientia Iranica, 23(2), pp. 535-547 (2016).

4. Makowski, Z.S. "Space structures of today and tomorrow", Journal of Constructional Steel Research, 6(1), p. 86 (1986).

5. Yuan, X.-F., Zhou, L., and Duan, Y.-F. "Singularity and kinematic bifurcation analysis of pin-bar mechanisms using analogous stiffness method", International 
Journal of Solids and Structures, 49(10), pp. 12121226 (2012).

6. Bălut, N. and Gioncu, V. "The influence of geometrical tolerances on the behaviour of space structures", International Journal of Space Structures, 15(3), pp. 189-194 (2000).

7. Kameshki, E.S. and Saka, M.P. "Optimum geometry design of nonlinear braced domes using genetic algorithm", Computers \& Structures, 85(1-2), pp. 71-79 (2007).

8. Jagannathan Dharapuram, S., Epstein Howard, I., and Christiano Paul, P. "Nonlinear analysis of reticulated space trusses", ASCE J Struct Div, 101(12), pp. 26412658 (1975).

9. Xiong, Z., Guo, X., Luo, Y., and Zhu, S. "Elastoplastic stability of single-layer reticulated shells with aluminium alloy gusset joints", Thin-Walled Structures, 115, pp. 163-175 (2017).

10. Ramalingam, R. and Jayachandran, S.A. "Postbuckling behavior of flexibly connected single layer steel domes", Journal of Constructional Steel Research, 114, pp. 136-145 (2015).

11. Kato, S., Kim, J.-M., and Cheong, M.-C. "A new proportioning method for member sections of single layer reticulated domes subjected to uniform and nonuniform loads", Engineering Structures, 25(10), pp. $1265-1278$ (2003).

12. Makowski, Z.S., Analysis, design, and construction of braced domes, Nichols Pub. Co., New York (1984).

13. Spillers, W.R. and Levy, R. "Truss design: two loading conditions with prestress", Computer-Aided Design, 16(6), p. 339 (1984).

14. Kani, I.M. and Heidari, A. "Automatic two-Stage calculation of bifurcation path of perfect shallow reticulated domes", Journal of Structural Engineering, 133(2), pp. 185-194 (2007).

15. Dulácska, E. and Kollár, L. "Buckling analysis of reticulated shells", International Journal of Space Structures, 15(3), pp. 195-203 (2000).

16. Bkachut, J. "Combined axial and pressure buckling of shells having optimal positive Gaussian curvature", Computers \& Structures, 26(3), pp. 513-519 (1987).

17. Chan, S.L. "A non-linear numerical method for accurate determination of limit and bifurcation points", International Journal for Numerical Methods in Engineering, 36(16), pp. 2779-2790 (1993).

18. Magnusson, A. "Treatment of bifurcation points with asymptotic expansion", Computers \& Structures, 77(5), pp. $475-484$ (2000).

19. Camescasse, B., Fernandes, A., and Pouget, J. "Bistable buckled beam and force actuation: Experimental validations", International Journal of Solids and Structures, 51(9), pp. 1750-1757 (2014).
20. Madhukar, A., Perlitz, D., Grigola, M., Gai, D., and Jimmy Hsia, K. "Bistable characteristics of thickwalled axisymmetric domes", International Journal of Solids and Structures, 51(14), pp. 2590-2597 (2014).

21. Plaut, R.H. "Snap-through of arches and buckled beams under unilateral displacement control", International Journal of Solids and Structures, 63, pp. 109113 (2015).

22. Plaut, R.H. "Snap-through of shallow reticulated domes under unilateral displacement control", International Journal of Solids and Structures, 148-149, pp. 24-34 (2018).

23. Kiyohiro, I., Kazuo, M., and Hiroshi, F. "Bifurcation hierarchy of symmetric structures", International Journal of Solids and Structures, 27(12), pp. 15511573 (1991).

24. Mahdavi, S.H., Razak, H.A., Shojaee, S., and Mahdavi, M.S. "A comparative study on application of Chebyshev and spline methods for geometrically nonlinear analysis of truss structures", International Journal of Mechanical Sciences, 101-102, pp. 241-251 (2015).

25. Khoei, A.R. and Moslemi, H. "3D modeling of damage growth and crack initiation using adaptive finite element technique", Scientia Iranica, 17(5), pp. 372-386 (2010).

26. Sabermahany, H., Vafai, A., and Mofid, M. "Dynamic response of concrete funicular shells with rectangular base under impulse loads", Scientia Iranica (2018).

27. Plaut, R.H. and Virgin, L.N. "Snap-through under unilateral displacement control with constant velocity", International Journal of Non-Linear Mechanics, 94, pp. 292-299 (2017).

28. Ma, H., Fan, F., Wen, P., Zhang, H., and Shen, S. "Experimental and numerical studies on a single-layer cylindrical reticulated shell with semi-rigid joints", Thin-Walled Structures, 86, pp. 1-9 (2015).

29. Reyhan, K., İpekoğlu, B., and Böke, H. "Construction techniques of domes in some Ottoman baths", Journal of Cultural Heritage, 14(3), Supplement, pp. e35-e40 (2013).

30. Crivelli, L.A., A Total-Lagrangian Beam Element for Analysis of Nonlinear Space Structures, University of Colorado at Boulder, Colorado (1991).

31. Расчет снеговой нагрузки: нормативная и расчетная снеговая, СП 20.13330.2011, in: Russia (Ed.).

32. Soetens, F. "Adhesive joints in aluminium alloy structures", International Journal of Adhesion and Adhesives, 10(3), pp. 146-152 (1990).

33. Kani, I.M. Theoretical and experimental investigation of collapse of shallow reticulated domes, Department of Engineering, University of Cambridge (1986).

\section{Biographies}

Alireza Heidari is a Postdoctoral Associate at McGill, Department of Mechanical Engineering and 
McGill University Health Centre (MUHC). He obtained his $\mathrm{PhD}$ in the field of Structural Mechanics from Russia and conducted a postdoctoral research on cardiovascular biomechanics at the University of Tehran in cooperation with Tehran Heart Center. Dr. Heidari is a structural mechanics expert with a focus on cardiovascular soft tissues. His past research includes studying the ratcheting mechanism and remodeling for the structure and material of cardiovascular tissues, and he also numerically studied the effects of a type of cardiac assist device on blood flow hemodynamics and perfusion in coronary arteries.

Hossein Karimi is a PhD Candidate at University of Tehran, Faculty of Engineering. He obtained MSc in the field of Structural Engineering from Sharif University of Technology, Department of Civil Engineering. Moreover, he received his BSc degree from the same university. Some of his research interests are linear and nonlinear finite element method in mechanic of materials, micro mechanics bio-mechanics and Nano-Mechanics, molecular dynamics and parallel multi-scale simulation and fracture frictional contract mechanics. He is interested in photography, nature, and Astrophotography.

Iradj Mahmoudzadeh Kani is a Professor at University of Tehran, Department of Civil Engineering, Faculty of Engineering, University of Tehran. He obtained his PhD in the field of Structural Engineering from University of Cambridge, Cambridge, UK. In addition, he had an MSc degree in Advanced Structural Engineering from the University of Southampton, Southampton, UK. Dr. Mahmoudzadeh is a Structural Engineer with a focus on design of heavy industrial complexes. He is the author of six books and more than 40 papers in related fields. He has taught academic courses from 1986 up to now. 